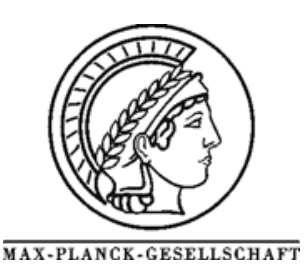

\title{
Interaction between Sulfated Zirconia and Alkanes: Prerequisites for Active Sites - Formation and Stability of Reaction Intermediates
}

\author{
X. Li ${ }^{\text {a }}$, K. Nagaoka ${ }^{\text {a }}$, L.J. Simon ${ }^{\text {a }}$, J.A. Lercher ${ }^{\text {a }}$, S. Wrabetz ${ }^{\text {b }}$, F.C. Jentoft ${ }^{b}$, C. Breitkopf ${ }^{\text {c }}$, \\ S. Matysik ${ }^{c}$, H. Papp ${ }^{\text {c* }}$ \\ ${ }^{a}$ Technische Universität München, Department of Chemistry, Lichtenbergstraße 4, 85747 Garching, Germany \\ ${ }^{\mathrm{b}}$ Department of Inorganic Chemistry, Fritz-Haber-Institute of the MPG, Faradayweg 4-6, 14195 Berlin, Germany \\ ${ }^{\mathrm{c}}$ Universität Leipzig, Institute of Technical Chemistry, Linnéstr. 3, 04103 Leipzig, Germany \\ ${ }^{*}$ Corresponding author
}

Received 22 September 2004; revised 24 November 2004; accepted 26

November 2004. Available online 13 January 2005.

\begin{abstract}
Two sulfated zirconia catalysts were prepared via sulfation and calcination at $873 \mathrm{~K}$ of zirconium hydroxide aged at room temperature for $1 \mathrm{~h}$ (SZ-1) or aged at $373 \mathrm{~K}$ for $24 \mathrm{~h}$ (SZ-2). SZ-1 was active for $n$-butane isomerisation at $373 \mathrm{~K}$; SZ-2 reached similar performance only at $473 \mathrm{~K}$. Both materials contained about $9 \mathrm{wt} \%$ sulfate and were tetragonal. Due to a BET lower surface area $\left(105 \mathrm{~m}^{2} / \mathrm{g} v \mathrm{vs} .148 \mathrm{~m}^{2} / \mathrm{g}\right) \mathrm{SZ}-1 \mathrm{fea}-$ tured a higher sulfate density, and XRD and EXAFS analysis showed larger (ca. $10 \mathrm{~nm}$ ) and more well ordered crystals than for SZ-2. $n$-Butane TPD on SZ-1 showed a butene desorption peak at low temperature, whereas, no obvious butene desorption was observed with SZ-2, suggesting that SZ-1 has a higher oxidizing power at low temperature than SZ-2. The number of sites capable of dehydrogenation are less than $5 \mu \mathrm{mol} / \mathrm{g}$, because the differential heats of $n$-butane adsorption as measured by microcalorimetry were $45-60 \mathrm{~kJ} / \mathrm{mol}$ for higher coverages, indicating weak and reversible interaction. TAP experiments describe the adsorption and desorption behavior of $n$-butane at different activity states and are the basis for a simple adsorption model. Reactant pulses and purge experiments show that the active species, presumably formed in an oxidative dehydrogenation step, are stable at the surface under reaction conditions.)
\end{abstract}

\section{Introduction}

Sulfated zirconia, capable of converting alkanes to their isomers at low temperatures, attracted significant interest in recent years [1, 2, 3, 4]. Even though numerous investigations focused on the preparation of sulfated zirconia, the essential procedure is still unclear, since many factors significantly affect the resultant sulfated zirconia, e.g., the precursor for sulfation $[5,6,7]$, the sulfation agent $[8,9]$, or the calcination conditions $[10,11,12,13,14]$.

It was claimed that an active sulfated zirconia can only be prepared from amorphous zirconia hydroxide [15], obtained from hydrolysis of zirconium salts, i.e., $\mathrm{ZrOCl}_{2}$, $\mathrm{ZrCl}_{4}$ or $\mathrm{ZrO}\left(\mathrm{NO}_{3}\right)_{2}$. Sulfation of crystalline zirconia was claimed to result in inactive sulfated zirconia. Recently, however, also the preparation of active sulfated zirconia by sulfation of crystalline zirconia has been reported [16, 17]. The calcination of sulfated amorphous zirconium hydroxide in the temperature range 723 to $923 \mathrm{~K}$ always yielded predominantly the metastable tetragonal zirconia phase, which was believed to be the catalytically active phase [18, 19, 20]. In spite of that, recently, monoclinic sulfated zirconia was also shown to be active for n-butane isomerization [21, 22], but the activity was lower than that of tetragonal zirconia.

When Arata et al. $[2,14]$ discovered the property of sulfated zirconia for butane isomerization at room temperature, it was categorized to be a superacid, since only superacids are claimed to activate light alkanes at such a temperature. However, experiments using NMR [23, 24], UV-vis [25], or IR spectroscopy [26, 27] revealed that the acidity of sulfated zirconia is not higher than that of sulfuric acid. Alternatively, the alkane isomerization may be related to the generation of olefins via oxidative processes $[28,29$, 
30]. In this context it should be mentioned that several papers demonstrated the promoting effect of butenes for $n$ butane isomerization, via formation of carbenium ions on the catalyst surface $[31,32,33]$.

In general, n-butane skeletal isomerization on sulfated zirconia or other sulfated metal oxide shows an induction period at low temperature, which is assumed to be due to the formation of the active species [34]. After the activity reaches its maximum, the catalyst deactivates, while coke is being formed on the surface [35]. The rate constant of deactivation decreased dramatically when alkenes in the feed were eliminated via a suitable trap [36, 37].

Here we use two sulfated zirconia materials of very different activity, but both tetragonal and equal in sulfate content, to discriminate on a finer scale between relevant and irrelevant properties. Besides extensive structural and site characterization we investigate the ability of the materials to generate butenes and the dynamics of the catalytic behavior with variations in reaction temperature and feed composition on a minute to hour scale.

\section{Experimental}

\subsection{Catalyst preparation}

Zirconium hydroxide powders were prepared by precipitation of $\mathrm{ZrO}\left(\mathrm{NO}_{3}\right)_{2}$ with $\mathrm{NH}_{4} \mathrm{OH}$ in water at $\mathrm{pH} 8.4$ with stirring. The resulting precipitate was aged in solution at room temperature for $1 \mathrm{~h}$ followed by filtering, washing, and drying at 373 393 K, denoted as Z-1. Alternatively, the precipitate was aged at $373 \mathrm{~K}$ for $24 \mathrm{~h}$ and processed as above; this sample is denoted as Z-2. Sulfated zirconias (SZ1 and SZ-2) were obtained by sulfating the powders prepared above (Z-1 and Z-2) with $(\mathrm{NH} 4)_{2} \mathrm{SO}_{4}(20 \mathrm{~mol} \%)$ followed by calcination at $873 \mathrm{~K}$ for $3 \mathrm{~h}$ in flowing air.

\subsection{Catalyst characterization}

The sulfate contents $\left(\mathrm{SO}_{4}{ }^{2-} \mathrm{wt} \%\right)$ of the catalysts were determined using ion chromatography (IC) as described in the literature [38]. For this, $0.02 \mathrm{~g}$ of sulfated zirconia was suspended in a $0.1 \mathrm{~N}$ solution of $\mathrm{NaOH}$ and the solution was filtered with a $0.45 \mu \mathrm{m}$ filter. The sulfate content was measured by ion chromatography (Metrohm, 690 ion chromatograph equipped with an IC anion column). The BET surface area of sulfated zirconia was determined using a PMI automated BET-sorptometer at $77.3 \mathrm{~K}$ using nitrogen as analysis gas. X-ray diffractometry (XRD) of the catalysts was performed in transmission geometry on a STOE STADI-P Xray diffractometer equipped with a primary monochromator and a curved position sensitive detector with an internal resolution of $0.01^{\circ}$, using $\mathrm{Cu} \mathrm{K} \alpha$ radiation $(\lambda=1.542 \AA)$. Samples were mixed 1:1 with corundum, which was employed as internal standard. Non-sulfated samples were analyzed with a Philips X'Pert-1, also using $\mathrm{CuK} \alpha$ radiation. Scanning electron microscopy (SEM) was conducted on a
Hitachi S-4000 microscope equipped with a cold field emission gun at an acceleration voltage of $5 \mathrm{kV}$. X-ray absorption spectra of the $\mathrm{Zr} \mathrm{K}$ edge $(17.998 \mathrm{keV})$ were recorded at beamline X1 at the Hamburger Synchrotron Radiation Laboratory, HASYLAB, using a $\mathrm{Si}(311)$ double crystal monochromator. The storage ring operated at $4.45 \mathrm{GeV}$ with injection currents of $150 \mathrm{~mA}$. X-ray absorption fine structure (XAFS) analysis was performed using the software package WinXAS v2 [39].

To estimate the concentration of Brønsted and Lewis acid sites, IR spectra for pyridine adsorption tests were carried out at $373 \mathrm{~K}$ in vacuum with a Perkin-Elmer 2000 spectrophotometer at $4 \mathrm{~cm}^{-1}$ resolution. Samples were pressed into wafers, heated to $673 \mathrm{~K}$ at $10 \mathrm{~K} / \mathrm{min}$, held at $673 \mathrm{~K}$ for 2 hours (residual pressure of $10^{-6} \mathrm{hPa}$ ), and exposed to pyridine $(0.1 \mathrm{hPa})$ at $373 \mathrm{~K}$ for $60 \mathrm{~min}$, followed by evacuation at this temperature for $30 \mathrm{~min}$. The number of sites available for alkane adsorption was determined by measuring adsorption isotherms of propane, $n$-butane, and isobutane (all Messer-Griesheim, $99.5 \%$ ) at $313 \mathrm{~K}$ following outgassing at $723 \mathrm{~K}$ in vacuum. The differential heats of adsorption were determined using a SETARAM MS-70 Calvet calorimeter. The setup is described in detail in [40]. The error bars given for the data result from the uncertainty in the heat generated by valve opening, which contributes to the heat signal of each dosing step.

\subsection{Temperature programmed desorption (TPD) of n-butane}

The temperature programmed desorption of $n$-butane was performed using a vacuum system. The sulfated zirconia sample was activated under vacuum at $673 \mathrm{~K}$ for $2 \mathrm{~h}$ and cooled to $323 \mathrm{~K}$ for $n$-butane adsorption. $2 \mathrm{hPa}$ of $n$-butane (Messer-Griesheim, $99.5 \%$, purified using a H-Y zeolite trap for alkene removal) was allowed to equilibrate with the sample for $5 \mathrm{~min}$. The sample was heated to $873 \mathrm{~K}$ at 10 $\mathrm{K} / \mathrm{min}$. The desorbing species were analyzed using a mass spectrometer (QME 200, Pfeiffer vacuum).

\subsection{Isomerization of n-butane}

$n$-Butane isomerization was carried out in a quartz micro tube reactor $(8 \mathrm{~mm}$ i.d.) under atmospheric pressure. Sulfated zirconia pellets $(0.2 \mathrm{~g}, 315 \sim 710 \mu \mathrm{m})$ were loaded into the reactor and activated in situ at $673 \mathrm{~K}$ for $2 \mathrm{~h}$ in flowing $\mathrm{He}(10 \mathrm{ml} / \mathrm{min})$. The catalyst was cooled to the desired reaction temperature and the reactant mixture $(5 \% n$-butane in He, total flow of $20 \mathrm{ml} / \mathrm{min}$ ) was flown through the catalyst bed. $n$-Butane (Messer-Griesheim, $99.5 \%$ ) was purified from alkene impurities by flushing it through a trap containing $\mathrm{H}-\mathrm{Y}$ zeolite. Alkenes were not detected in the reactant mixture after purification. The reaction products were analyzed using an on-line HP 5890 gas chromatograph (GC) equipped with a capillary column (Plot $\mathrm{Al}_{2} \mathrm{O}_{3}, 50 \mathrm{~m} \times 0.32$ $\mathrm{mm} \times 0.52 \mathrm{~mm}$ ) connected to a flame ionization detector 
(FID). The rate of isobutane formation was taken as a measure of catalytic activity.

The influence of temperature on the catalytic behavior of both catalysts was studied. After reaction at $373 \mathrm{~K}$ over $60 \mathrm{~h}$, when SZ-1 was deactivated completely while SZ-2 had not shown any activity, $20 \mathrm{ml} / \mathrm{min}$ of He flow was flown through the catalyst bed for $30 \mathrm{~min}$. The reaction was then restarted after the temperature had been increased to $473 \mathrm{~K}$.

Pulsing during the induction period of the reaction on SZ-1 at $373 \mathrm{~K}$ was performed by alternatively changing the reactant (5\% n-butane) and He flow every $1 \mathrm{~min}$. A stoprestart experiment was conducted on the SZ-1 catalyst at $373 \mathrm{~K}$ during the deactivation phase. At the end of the induction period, the catalyst bed was purged with $\mathrm{He}$ for a certain time, and then the reaction was restarted. This procedure was repeated several times.

\subsection{TAP- Temporal Analysis of Products - switch experiments with $n$-butane}

Surface sites and their reactivity were probed in the TAP-II reactor [40] by pulsing $n$-butane over the fresh catalysts and over catalysts that had been operated in isomerization in a flow experiment at $423 \mathrm{~K}$. Pulse responses were analyzed using a quadrupole mass spectrometer (QMS) from HIDEN, where single masses $(\mathrm{m} / \mathrm{e})$ of interest can be followed. The reactor was filled with a corundum/catalyst mixture analogous to atmospheric flow experiments. For SZ-1, $300 \mathrm{mg}$ of catalyst were used, filled up with $700 \mathrm{mg}$ corundum whereas for SZ-2, which is more voluminous, $258 \mathrm{mg}$ catalyst material was mixed with $604 \mathrm{mg}$ corundum. The particle diameter for all materials was $0.1-0.315 \mathrm{~mm}$. The temperature was controlled by a thermocouple positioned in the center of the bed.

Neon was taken as reference gas. Knudsen diffusion in the reactor during pulse experiments was ensured by controlling the pulse intensity of the pulses. The shape of the response curves has to be independent from the pulse size. Pulse sizes were then kept constant. Reactant mixtures were used at a constant pulse width of $130 \mu$ s mixed up in the blending tank with $200 \mathrm{hPa}$ inert gas and $200 \mathrm{hPa}$ reactant gas. A single experiment consisted of several cycles of pulsing with signal averaging (in general 10 pulses; for $\mathrm{m} / \mathrm{e}$ of lower intensity up to 50) to improve the signal-to-noise ratio.

Samples were activated before use in TAP at $573 \mathrm{~K}$ for $2 \mathrm{~h}$ in vacuum in the microreactor and then cooled down with $10 \mathrm{~K} / \mathrm{min}$ to the reaction temperature. The fresh samples were exposed to single pulses of $n$-butane (MesserGriesheim $99.5 \%$ ) first. The flow experiments were conducted by closing the slide valve of the TAP reactor and exposing the microreactor to a constant flow of $2 \mathrm{ml} \mathrm{n}$ butane (Messer-Griesheim 99.95\%) in $18 \mathrm{ml}$ helium. The reaction products were analyzed with on line GC (Shima$\mathrm{dzu})$.

$n$-Butane was monitored at all possible fragments known for $\mathrm{C}_{4}$ alkanes. Only their main mass fragments $\mathrm{m} / \mathrm{e}$ $=27,29,41,43,58$ and their ratios will be discussed in detail here.

Modeling of a simple first order adsorption rate constant was performed with help of the modeling software by Schuurman and Gleaves [41] which assumes a first order Langmuir adsorption for the reactant in a one zone model.

\section{Results}

\subsection{Catalyst characterization}

BET surface areas, pore sizes, particle sizes, sulfate contents and acid concentrations of different samples are compiled in Table 1. The zirconium hydroxide samples without thermal treatment exhibited the highest BET surface areas, i.e. uncalcined Z-1, $288 \mathrm{~m}^{2} / \mathrm{g}$ and uncalcined Z-2, $342 \mathrm{~m}^{2} / \mathrm{g}$. Calcination at $873 \mathrm{~K}$ for $3 \mathrm{~h}$ converted zirconium hydroxide to zirconia and caused a significant BET surface area decrease, i.e., calcined Z-1, $49 \mathrm{~m}^{2} / \mathrm{g}$ and calcined Z-2, $76 \mathrm{~m}^{2} / \mathrm{g}$. Calcination at $873 \mathrm{~K}$ for $3 \mathrm{~h}$ of zirconium hydroxide doped with sulfate also resulted in a loss of BET surface area decrease,

Table 1 (a) Preparation and properties of raw materials

\begin{tabular}{|c|c|c|c|c|}
\hline Sample name & $\begin{array}{c}\text { Z-1 } \\
\text { uncalcined }\end{array}$ & SZ-1 uncalcined & $\begin{array}{c}\mathrm{Z}-2 \\
\text { uncalcined }\end{array}$ & SZ-2 uncalcined \\
\hline Precursor & \multicolumn{4}{|c|}{ Precipitation from $\mathrm{ZrO}\left(\mathrm{NO}_{3}\right)_{2}$ with $\mathrm{NH}_{4} \mathrm{OH}$ until $\mathrm{pH} 8.4$} \\
\hline Aging & \multicolumn{2}{|c|}{$1 \mathrm{~h}$ at room temperature } & \multicolumn{2}{|c|}{$24 \mathrm{~h}$ at $373 \mathrm{~K}$} \\
\hline Drying & \multicolumn{4}{|c|}{ After filtering and washing dried at $373-393 \mathrm{~K}$} \\
\hline Sulfation & - & $\begin{array}{c}\left(\mathrm{NH}_{4}\right)_{2} \mathrm{SO}_{4} \\
20 \mathrm{~mol} \%\end{array}$ & - & $\begin{array}{c}\left(\mathrm{NH}_{4}\right)_{2} \mathrm{SO}_{4} \\
20 \mathrm{~mol} \%\end{array}$ \\
\hline $\mathrm{SO}_{4}{ }^{2-}(\mathrm{wt} \%)$ & - & 13.4 & - & n.d. \\
\hline BET surface area $\left(\mathrm{m}^{2} / \mathrm{g}\right)$ & 288 & n.d. & 342 & n.d. \\
\hline
\end{tabular}


(b) BET surface area, pore size, crystallite size, sulfate content and acid concentration

\begin{tabular}{|c|c|c|c|c|}
\hline Sample name & Z-1 calcined & SZ-1 calcined & Z-2 calcined & SZ-2 calcined \\
\hline Calcination & \multicolumn{4}{|c|}{ Flowing air, $873 \mathrm{~K}, 3 \mathrm{~h}$} \\
\hline BET surface area $\left(\mathrm{m}^{2} / \mathrm{g}\right)$ & & & & \\
\hline & 49 & 105 & 76 & 148 \\
\hline Pore size $(\mathrm{nm})$ & 8.0 & 3.5 & 7.0 & 3.7 \\
\hline Crystallite size (nm) & & & & \\
\hline & 12.6 & 9.9 & 11.0 & 7.5 \\
\hline $\mathrm{SO}_{4}^{2-}(\mathrm{wt} \%)$ & - & 9.0 & - & 8.9 \\
\hline $\begin{array}{c}\mathrm{SO}_{4}{ }^{2-} \mathrm{H}_{2} \mathrm{O} \text { leached } \\
(\mathrm{wt} \%)\end{array}$ & - & 2.5 & - & 3.0 \\
\hline $\begin{array}{l}\text { Brønsted acid sites } \\
\qquad(\mathrm{mmol} / \mathrm{g}) \\
\left(\mu \mathrm{mol} / \mathrm{m}^{2}\right)\end{array}$ & n.d. & $\begin{array}{c}0.069 \\
0.66\end{array}$ & n.d. & $\begin{array}{c}0.047 \\
0.32\end{array}$ \\
\hline $\begin{array}{l}\text { n-butane adsorption } \\
(\mathrm{mmol} / \mathrm{g}) \text { at } 1 \mathrm{kPa} \\
\left(\mu \mathrm{mol} / \mathrm{m}^{2}\right) \text { at } 1 \mathrm{kPa}\end{array}$ & n.d. & $\begin{array}{c}0.062 \\
0.51\end{array}$ & n.d. & $\begin{array}{l}0.056 \\
0.38\end{array}$ \\
\hline
\end{tabular}

i.e., calcined Z-1, $49 \mathrm{~m}^{2} / \mathrm{g}$ and calcined Z-2, $76 \mathrm{~m}^{2} / \mathrm{g}$. Calcination at $873 \mathrm{~K}$ for $3 \mathrm{~h}$ of zirconium hydroxide doped with sulfate also resulted in a loss of BET surface area. However, the calcined sulfate doped samples had higher BET surface areas than the calcined undoped samples, i.e. SZ-1, $105 \mathrm{~m}^{2} / \mathrm{g}$ and SZ-2, $148 \mathrm{~m}^{2} / \mathrm{g}$, (twice that of calcined $\mathrm{Z}-1$ and Z-2, respectively). The pore and particle size dis
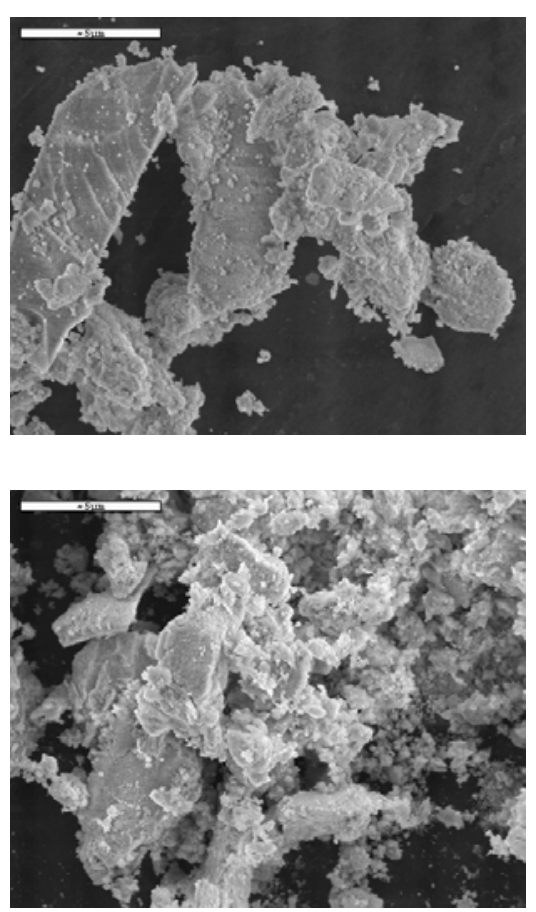

Figure 1: SEM images of (a) SZ-1 and (b) SZ-2. tributions of the calcined samples indicate that the calcined sulfate-doped and undoped zirconia samples were all mesoporous materials with irregular pores. The difference in morphology of SZ-1 and SZ-2 becomes evident from scanning electron microscopy, see Figure 1. The SZ-1 particles were typically $5-20 \mu \mathrm{m}$ in size; the surfaces exhibit smooth and stepped regions, and often smaller particles were adhering. SZ-2 consisted predominantly of particles $1-5 \mu \mathrm{m}$ in diameter, which occasionally enveloped larger particles.

Figure 2a shows the XRD patterns for SZ-1, SZ-2, Z1 and $\mathrm{Z}-2$, which were all calcined at $873 \mathrm{~K}$ for $3 \mathrm{~h}$ in air. The calcined Z-1 was monoclinic and calcined Z-2 was tetragonal, which indicates that Z-1 was more sensitive to the thermal treatment than Z-2. Both calcined sulfated materials exhibited only reflections of the tetragonal phase. Normalization to internal standard corundum demonstrates that the reflections of SZ-2 are lower in intensity and broader those of SZ-1 (Figure 2b). The sizes of the crystalline domains as obtained via the Scherrer equation were 9.9 $\mathrm{nm}$ for SZ-1 and $7.5 \mathrm{~nm}$ for SZ-2.

These findings are corroborated by Zr K edge XAFS (see Figure 3). The radial distribution functions, consistent with tetragonal or cubic zirconia, showed a lower intensity in the second and higher maxima for SZ-2 than for SZ-1. These higher shells are dominated by $\mathrm{Zr}-\mathrm{Zr}$ contributions, and the decreased intensity may indicate a reduction in the $\mathrm{Zr}-\mathrm{Zr}$ coordination due to smaller crystal domains. Additionally, the reduced intensity may indicate an increase in the disorder of the structure, caused by strain, a small amount of a less ordered crystalline or amorphous $\mathrm{ZrO}_{2}$ phase. 

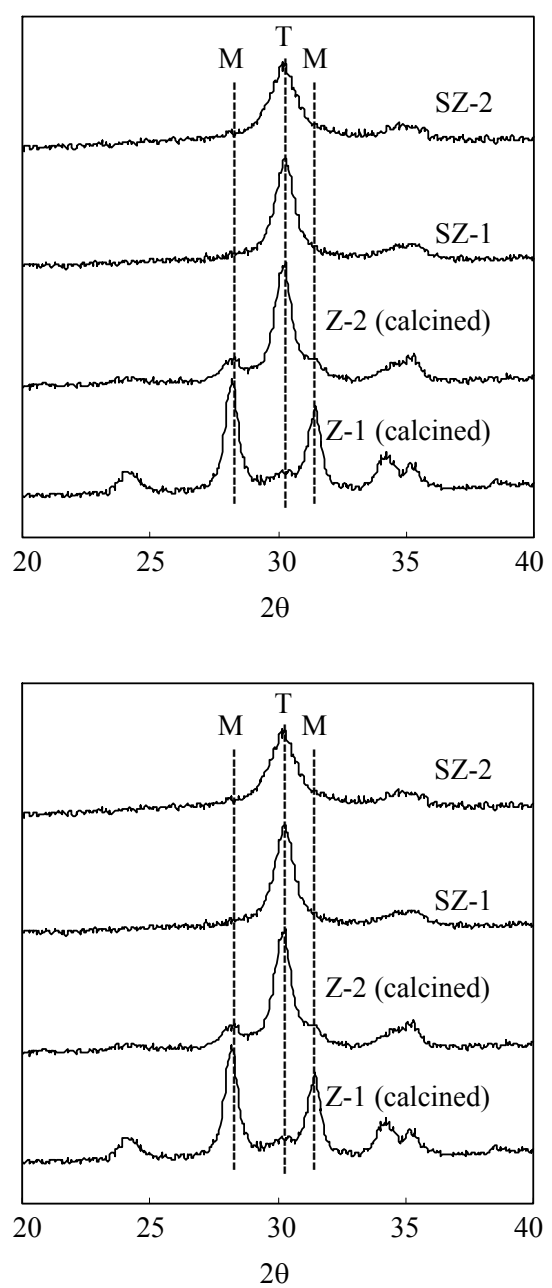

Figure 2: XRD patterns of (a) calcined Z-1, Z-2, SZ-1 and SZ-2 and (b) calcined SZ-1 and SZ-2 measured with internal standard. M, monoclinic phase; T, tetragonal phase; *, internal standard corundum

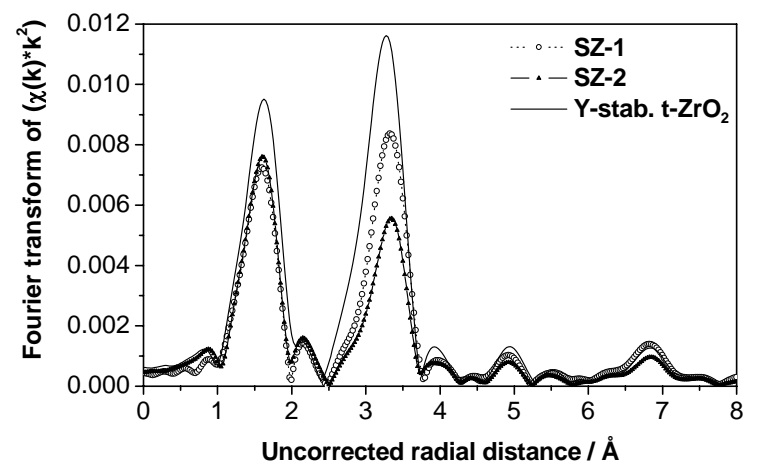

Figure 3: Uncorrected radial distribution function for $\mathrm{Zr} \mathrm{K}$ edge of SZ-1, SZ-2 and an yttria-stabilized reference material.

\subsection{Surface Sites}

The sulfate content of the uncalcined SZ-1 was $13.4 \%$, while calcination at $873 \mathrm{~K}$ for $3 \mathrm{~h}$ in air resulted in a sulfate content of $9.0 \mathrm{wt}$. \%, which indicates that the high temperature treatment eliminated approximately $30 \%$ of the sulfate groups. The sulfate contents of the resulting two calcined sulfated zirconia samples, SZ-1 and SZ-2, were both $9 \%$ in $\mathrm{SO}_{4}{ }^{2-}$ wt $\%$. This is higher than a hypothetical monolayer, if $0.31 \mathrm{~nm}^{2}$ is assumed to be the surface area occupied by a $\mathrm{SO}_{4}{ }^{2-}$ group based on its kinetic diameter [42]. The water-soluble sulfate fractions were 2.5 and 3.0 $\mathrm{wt} \%$ for SZ-1 and SZ-2, respectively.

The Brønsted acid site concentration (determined by adsorption of pyridine) of calcined SZ-1 was $0.069 \mathrm{mmol} / \mathrm{g}$, which is higher than $0.047 \mathrm{mmol} / \mathrm{g}$ observed with calcined SZ-2. Thus, SZ-1 provides 1.5 times as many Brønsted sites as SZ-2. This ratio was also confirmed with impedance spectroscopy, with which the relative concentrations of protonated pyridine molecules were also explored [43].

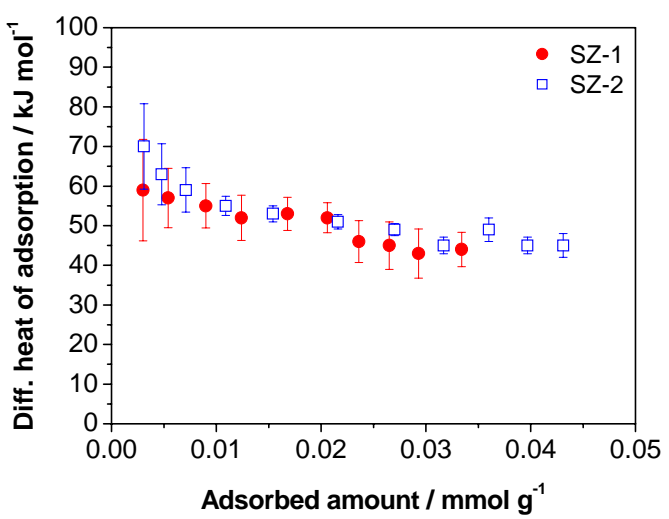

Figure 4: Differential heats of adsorption of $n$-butane on SZ-1 and SZ-2 as a function of coverage. Activation at $723 \mathrm{~K}$ in vacuum, adsorption at $313 \mathrm{~K}$.

Alkane sorption sites on both materials were probed by adsorption of propane and butanes. Adsorption isotherms could be adequately described by a first order Langmuir model for low pressures. The curvature at higher pressures could be reproduced by using a higher order Langmuir model, but a slightly better fit was obtained with a Freundlich model. The differential heats decline with coverage, which is considered in the Freundlich model; but the decline is very gentle so that the Langmuir model, which assumes uniform heats, is still a reasonable match. The Freundlich isotherms were used to estimate the number of sites covered at the typical alkane partial pressure of 5 $\mathrm{kPa}$. Typical $\mathrm{C}_{4}$ coverages at $5 \mathrm{kPa}$ were between 85 and $160 \mu \mathrm{mol} \mathrm{g}^{-1}$. The difference in the concentration of sites between the two catalysts, however, was not larger than differences arising through variation of the activation temperature. The heats of adsorption decreased slightly with coverage. For all three alkanes on both catalysts, differential heats of about $60 \mathrm{~kJ} \mathrm{~mol}^{-1}$ were determined at ca. 5 $\mu \mathrm{mol} \mathrm{g} \mathrm{g}^{-1}$ coverage. The heats slowly declined to about 45 $\mathrm{kJ} \mathrm{mol}^{-1}$ at $30 \mu \mathrm{mol} \mathrm{g}{ }^{-1}$ coverage. The presence of a small amount of sites (i.e. $<5 \mu \mathrm{mol} \mathrm{g}{ }^{-1}$ ) with a different heat of adsorption cannot be excluded; however, data scatter considerably at coverages below $2-5 \mu \mathrm{mol} \mathrm{g}{ }^{-1}$. For the major- 
ity of sites, there were no significant differences between SZ-1 and SZ-2 in the differential heats (see example $n$ butane adsorption, Figure 4).

\section{3. n-Butane temperature programmed desorp- tion (TPD)}

Figure $5(\mathrm{a}, \mathrm{b})$ shows the TPD after $n$-butane was adsorbed at $323 \mathrm{~K}$ on sulfated zirconia samples $\mathrm{SZ}-1$ and SZ-2. Butene $(\mathrm{m} / \mathrm{e}=56)$ was the most abundant desorbing species with an intense peak at $430 \mathrm{~K}$ on SZ-1. However, no obvious butene desorption peak was observed in $n$-butane TPD on SZ-2 at this temperature. Much lower intensities of butene and butane were observed in the gas phase up to $700 \mathrm{~K}$ for both catalysts, SZ-1 and SZ-2.
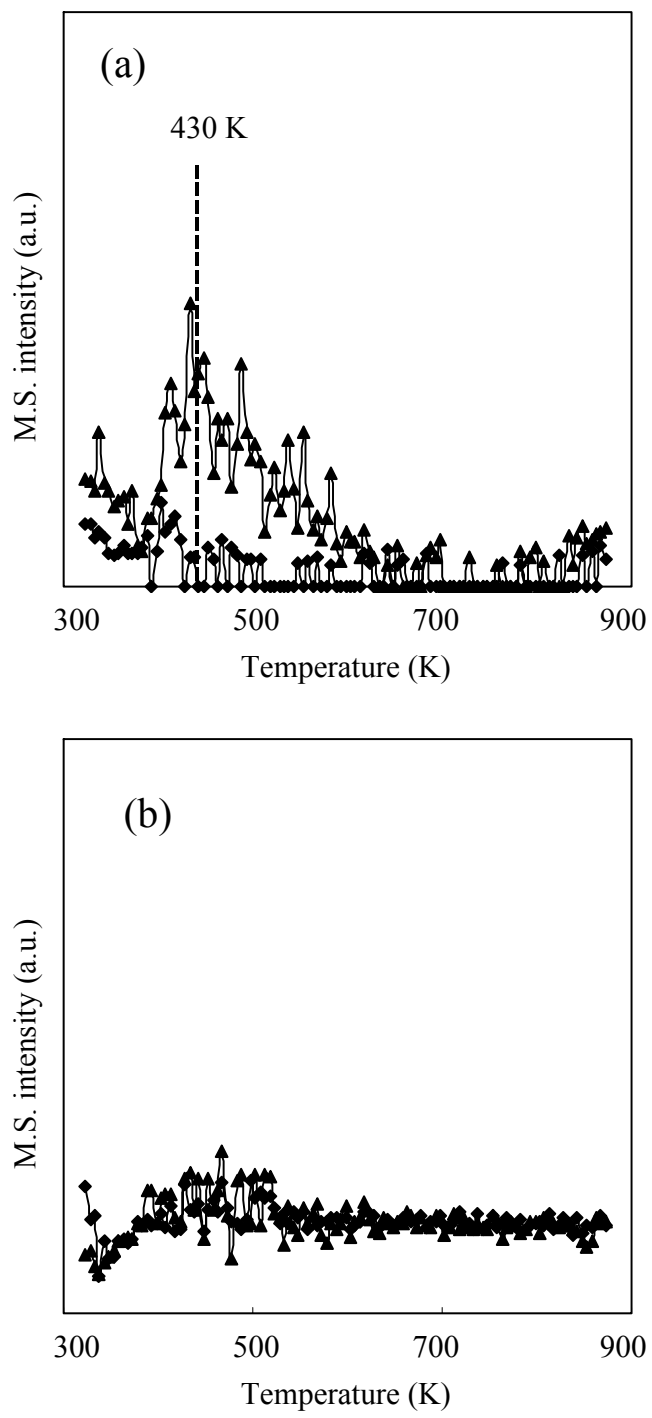

Figure 5: $n$-Butane TPD profiles (a) SZ-1 and (b) SZ-2, $(\boldsymbol{\Delta})$ butene $(\mathrm{m} / \mathrm{e}=56),(\diamond)$ butane $(\mathrm{m} / \mathrm{e}=58)$.

\subsection{Catalytic experiments at atmospheric pres- sure}

\subsubsection{Activity of n-butane isomerization on SZ-1 and SZ-2}

Figure 6 shows the $n$-butane isomerization activity versus time on stream (TOS) of SZ-1 and SZ-2 at $373 \mathrm{~K}$. SZ-1 showed a much higher catalytic activity than SZ-2, which was almost inactive at $373 \mathrm{~K}$ and the conditions used. An induction period characterized by a steady increase in the catalytic activity was observed during $n$ butane reaction on SZ-1, followed by deactivation. The maximum conversion for SZ-1 at $373 \mathrm{~K}$ was $0.9 \%$. The product of $n$-butane reaction is primarily isobutane with 95-96 \% selectivity. The main byproducts are propane and pentanes (n-pentane and iso-pentane with a ratio of 1:4).

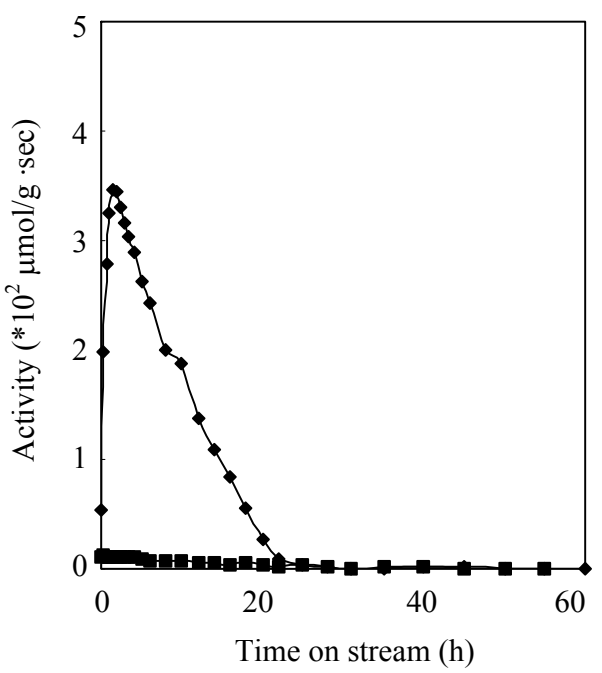

Figure 6: $n$-Butane reaction rate versus time on stream at $373 \mathrm{~K}$ on $(\bullet)$ SZ-1 and $(\boldsymbol{\square})$ SZ-2.

Figure 7 shows the Arrhenius correlation of $n$-butane isomerization on SZ-1 at reaction temperature from $333 \mathrm{~K}$ to $393 \mathrm{~K}$, where the maximum reaction rates were used as intrinsic activity. The apparent activation energy for $n$ butane conversion on SZ-1 of $41.5 \mathrm{~kJ} / \mathrm{mol}$ is in agreement with results reported previously [28, 34, 44]

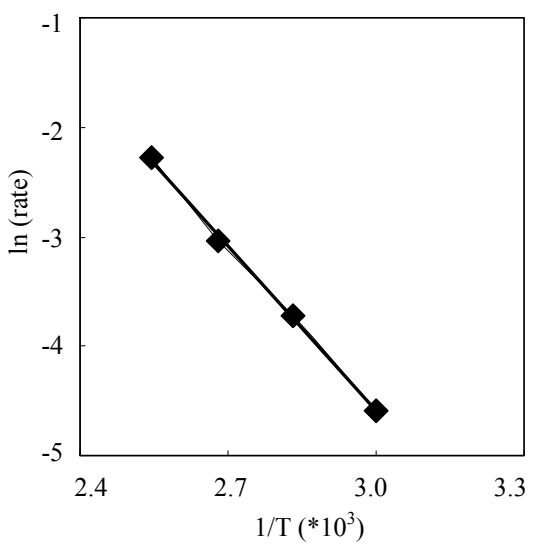

Figure 7:Arrhenius profile of $n$-butane isomerization on SZ-1 at temperature range of 333-393 K. 
Because SZ-2 showed no catalytic activity at $373 \mathrm{~K}$ for $n$-butane isomerization, we switched to He after $40 \mathrm{~h}$ and purged for $25 \mathrm{~h}$, then we increased the temperature to $473 \mathrm{~K}$ and tested again the catalytic performance (see Figure 8). Even though SZ-2 is almost inactive at $373 \mathrm{~K}$, it showed activity for $n$-butane isomerization at $473 \mathrm{~K}$, and the rate was in the same order as that of SZ-1 at $373 \mathrm{~K}$. The selectivity to isobutane was $96-97 \%$ with SZ-2 at $473 \mathrm{~K}$ and the major by-products were propane and pentane. SZ-2 deactivated only slowly.

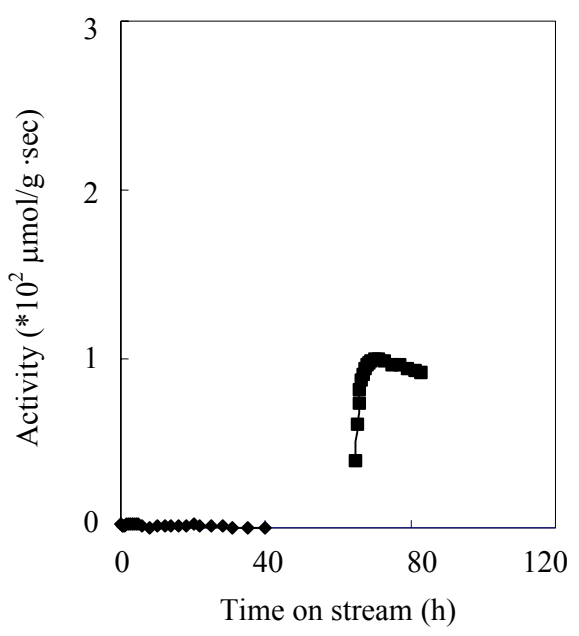

Figure 8: $n$-Butane reaction rate on SZ-2 versus time on stream at $(\diamond) 373 \mathrm{~K}$ followed by reaction at $(\boldsymbol{\square}) 473 \mathrm{~K}$.

\subsubsection{Pulsed reaction mode during the induction period}

A pulse method was applied in this study to explore the catalytic behavior during the induction period. He and reactant were alternatively replaced every $1 \mathrm{~min}$ and flown into the reactor for the first $60 \mathrm{~min}$ during $n$-butane reaction at $373 \mathrm{~K}$ on SZ-1 (see Figure 9). The overall reaction be-

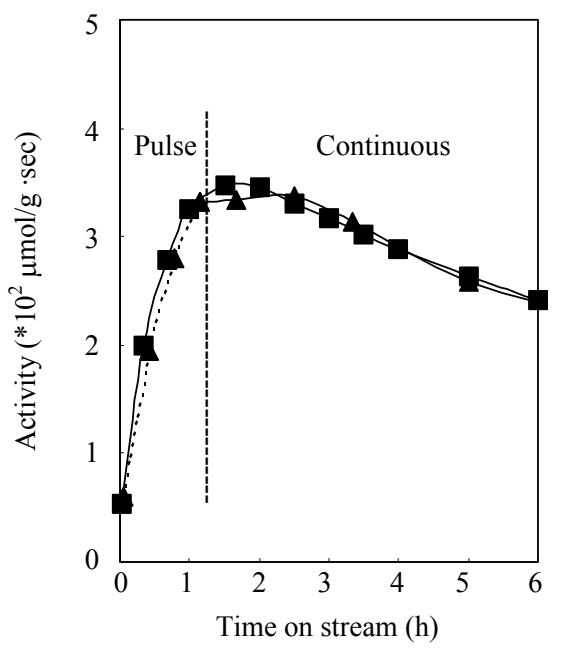

Figure 9: $n$-Butane reaction rate on SZ-1 at $373 \mathrm{~K}(\boldsymbol{\square})$ continuous reaction and $(\boldsymbol{\Delta})$ pulse reaction during induction period (alternative pure helium and reactant per $1 \mathrm{~min}$ ). havior was identical to the reaction with continuous flow, which indicates that the $1 \mathrm{~min}$ He purge did not affect the formation of active species. After the pulse reaction, a continuous flow of reactant was used to test the catalytic behavior in the deactivation period. It was also identical to the conventional continuous flow reaction.

\subsubsection{Stopping and restarting the reaction}

The stability of the active species on the catalytic surface was also investigated with stopping and restarting the reaction during the deactivation phase. Figure 10 shows that even after 20,60, $300 \mathrm{~min} \mathrm{He}$ purge, the catalyst showed high activity for $n$-butane isomerization without signs of a period of increasing activity. The average activity was nearly identical to that observed during the continuous flow mode operation. It is obvious that the active species, the carbenium ion (alkoxy group) is stable at $373 \mathrm{~K}$ on the catalyst surface and is removed by He purge. However, the initial activity after the restart was always higher than that at steady state indicating higher concentration of active species on the surface, which decreases to steady state values after a short time.

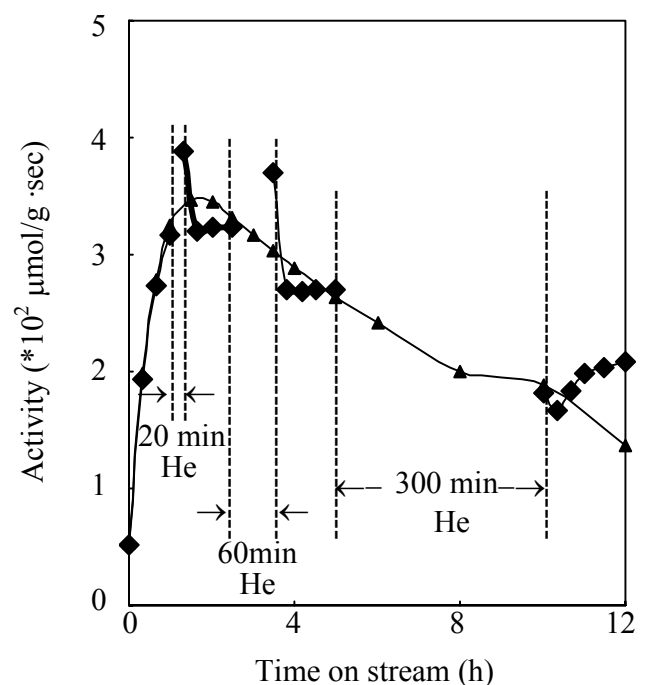

Figure 10: $n$-Butane reaction rate on SZ-1 at $373 \mathrm{~K}(\boldsymbol{\Delta})$ continuous reaction and $(\bullet)$ stop-restart reaction during deactivation period.

\subsection{TAP experiments on catalysts during con- tinuous flow operation}

TAP experiments were conducted intermittently with flow experiments to investigate the adsorption and desorption during various stages of the life cycle of sulfated zirconia.

The TAP intensity profiles recorded at $423 \mathrm{~K}$ for the 43 (main fragment of $n$ - and isobutane) are presented in Figure 11. All measured data represent the overall response, which is determined by adsorption, desorption and reaction [41]. As a single mass unit to follow the formation 
of products does not exist, fragmentation ratios are compared. Differences in the fragmentation patterns are thought to represent different surface processes and indicate indirectly the formation of products. Side product detection is also difficult due to the low intensities and the superposition of single mass fragments.
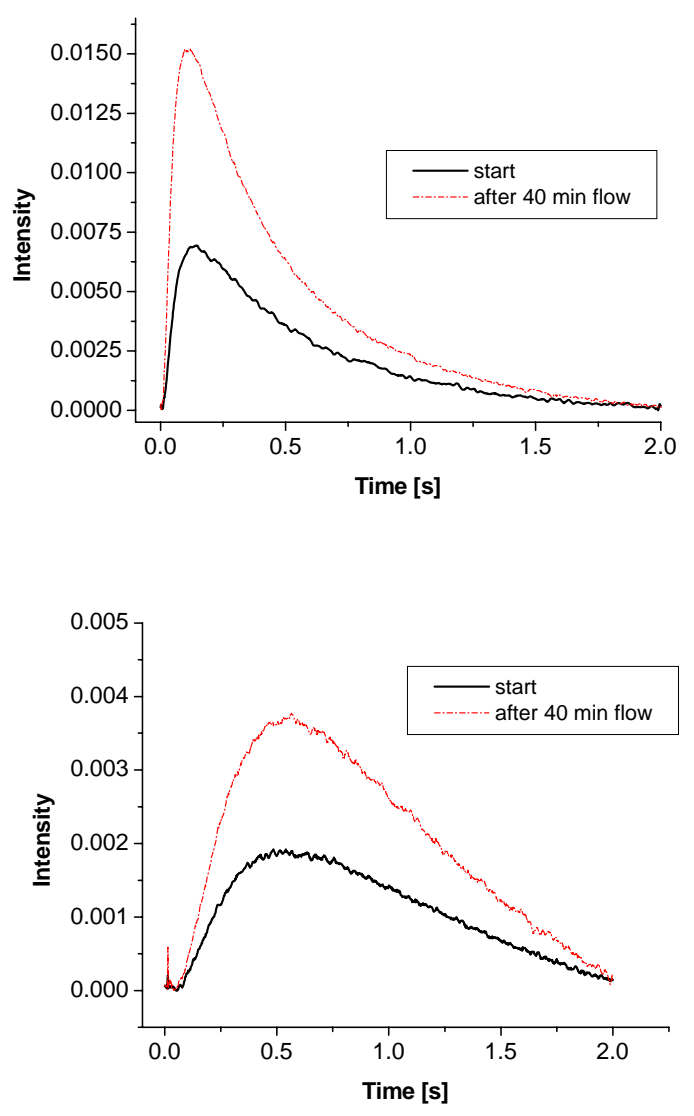

Figure 11: TAP response pulses for $n$-butane $(\mathrm{m} / \mathrm{e}=43)$ at $423 \mathrm{~K}$ for two different reactivity states of the catalysts (a) SZ-1, (b) SZ-2.
Relative to the inert materials corundum or unsulfated zirconia, the profile for the fresh SZ-1 was lower in intensity (not shown here). This consistently points towards a strong interaction of $n$-butane and/or isobutane with SZ-1. The residence time (and hence the strength of interaction) increased in the presence of surface sulfates, as evidenced by comparison of residence times between sulfated and nonsulfated samples.

After pulsing in vacuum, the operation mode was switched to flow conditions at atmospheric pressure for distinct time intervals. SZ-1 converted initially about $15 \%$ $n$-butane to isobutane and traces of propane and pentanes. With time on stream, SZ-1 deactivated to about $2 \%$ conversion after $120 \mathrm{~min}$. After $40 \mathrm{~min}$, the flow was stopped and it was switched back to vacuum and $n$-butane pulses were admitted again. The residence times and fragmentation patterns discussed here are taken from pulsing after 40 min treatment in $n$-butane flow, when SZ-1 is still active.

Table 2 summarizes all calculated fragmentation ratios. The comparison of the fragmentation ratios for SZ-1 (start values as reference) and SZ-1 (40 min) clearly shows that consistent with GC analysis the conversion from $n$ butane to isobutane can be followed by changes of the main fragments 43, 27, 29, 41 and 58 here. All measured intensities vary in their intensities and fragmentation ratios. Due to possible irreversible adsorption on the surface during pulsing and flow the mass balance is affected and may influence the measured ratios as well.

In the TAP experiment, three trends were observed with increasing deactivation of SZ-1: (i) the intensity of the peaks slowly recovered compared to the inert material and increased (Figure 11a), (ii) the residence times decreased, and (iii) the ratio of the $\mathrm{m} / \mathrm{e} 43$ to 58 fragments decreased (Table 3).

Table 2: Fragmentation pattern for SZ-1 and SZ-2 for fresh and deactivated catalysts (ratios of different mass fragments)

\begin{tabular}{|l|l|l|l|l|l|l|l|}
\hline & $43 / 20$ & $58 / 20$ & $43 / 58$ & $27 / 20$ & $29 / 20$ & $41 / 20$ & $42 / 20$ \\
\hline SZ-1, fresh & 1.73 & 0.18 & 9.31 & 1.82 & 1.96 & 0.33 & 0.43 \\
\hline SZ-1, 40 min & 2.55 & 0.31 & 8.09 & 2.07 & 2.27 & 1.15 & 0.48 \\
\hline SZ-2, fresh & 1.18 & 0.13 & 9.12 & 1.13 & 1.24 & 0.58 & 0.28 \\
\hline SZ-2, 40 min & 1.40 & 0.15 & 9.20 & 1.39 & 1.43 & 0.69 & 0.29 \\
\hline
\end{tabular}

Table 3: Comparison of residence times [s] for SZ-1 and SZ-2 for fresh and $40 \mathrm{~min}$ used catalysts ( $\mathrm{m} / \mathrm{e}=43$ ); over corundum $\tau=0.08 \mathrm{~s}, \mathrm{~T}=423 \mathrm{~K}$

\begin{tabular}{|l|l|l|}
\hline & SZ-1 & SZ-2 \\
\hline fresh & 0.52 & 0.84 \\
\hline 40 min catalysis & 0.46 & 0.83 \\
\hline
\end{tabular}


It is now interesting to compare the observed fragmentation ratios for the SZ-2 with the same experimental setup. The measured response curves for SZ-2 (inactive under the conditions chosen) are shown in Figure 11b. The displayed $\mathrm{m} / \mathrm{e} 43$ responses were reduced in their intensities relative to an inert material, too (inert material not shown). $n$-Butane is also strongly adsorbed on the surface of the material. The shape of the curves was broadened compared to SZ-1 and the residence time for the alkane was much higher than observed for SZ-1. Evaluation of the online GC data revealed that no significant conversion of $n$-butane to isobutane was observed. This is also displayed by the constant fragmentation ratios of SZ-2 for the start reference values and the $40 \mathrm{~min}$ fragmentation pattern. With time on stream the intensity of the main fragments also increased but their relations stay constant. Only adsorption and desorption determine the observed fragmentation ratios.

Modeling of the first step of the $n$-butane interaction with the catalyst surface was done with a simple one zone model assuming first order adsorption of the reactant. Comparison of the modeled adsorption rate constants for the fresh and used SZ-1 showed a significant decrease. As all parameters in the modeling are the same, the only variable, which causes this decrease, is the number of available adsorption sites on the catalyst surface. Thus, it can be concluded that after 40 min treatment of SZ-1 under flow conditions nearly half of the available adsorption places are blocked or deactivated. It has to be noticed that in that simple model no term for reaction to the product is included. For SZ-2 the trend was opposite to that observed for SZ-1. After 40 min treatment the adsorption rate constant was increased by a factor of 2.5 , which can only be interpreted such that adsorption sites centers have been created.

\section{Discussion}

\subsection{Prerequisites for active sites}

It has been discussed for some time that an active sulfated zirconia catalyst must consist of the tetragonal phase, which is metastable below $1300 \mathrm{~K}$. Only a few exceptions claimed a monoclinic or a mixture of monoclinic and tetragonal sulfated zirconia to be active for $n$-butane isomerization $[21,22]$. In this study, however, two tetragonal sulfated zirconia samples prepared from zirconium hydroxides with different aging conditions exhibited very different catalytic activity for $n$-butane reaction at low temperature. The tetragonal phase can, thus, be seen as a necessary but not as a sufficient requirement for good catalytic activity, which is consistent with the findings by Yang et al. [45].

Recent investigations by Li et al. [30] suggest that the isomerization reaction is initiated via oxidative dehydrogenation of $n$-butane by a pyrosulfate group $\left(\mathrm{S}_{2} \mathrm{O}_{7}{ }^{2-}\right)$. According to DFT calculations by Hofmann and Sauer [46], pyrosulfate is a possible and stable structure at the tetragonal (101) face. Following this hypothesis, two ex- planations emerge for the lower reactivity of SZ-2 in comparison to SZ-1, both based on the question as to which circumstances will favor the formation of pyrosulfate.

SZ-1 and SZ-2 differ in the size of the crystalline domains (XRD) and, moreover, the short-range order $(<8$ $\AA$ ) of their structures is also decidedly different ( $\mathrm{Zr} \mathrm{K}$ edge XAFS). Such variations in the bulk structure may lead to variations in the surface structure; more explicitly, the poorly crystallized, maybe highly defective tetragonal phase of SZ-2 may not be a suitable substrate for pyrosulfate. The pyrosulfate configuration on the zirconia surface is tetradentate, i.e., the three oxygen atoms of the pyrosulfate are connected to three surface zirconium atoms, and a forth oxygen is hydrogen-bridged to a water molecule adsorbed on a forth zirconium atom. While the fourth link can be considered as flexible, the other three bonds require three zirconium atoms arranged in an isosceles triangle. The lower intensity of the second shell in the EXAFS analysis of SZ-2 indicates that there are fewer zirconium atoms with the next zirconium neighbor at a distance corresponding to those of the tetragonal phase, implying that the described triangular configuration on the tetragonal (101) face is less abundant. The pyrosulfate, which is already strained on a perfect (101) face, may not be able to accommodate for aberrations in the distances, while, e.g., a bidentate monosulfate structure can.

The two samples SZ-1 and SZ-2 exhibit the same sulfate content, but different surface areas, resulting in different sulfate densities on the surface. The sulfate content is higher than required for a hypothetical monolayer coverage, i.e. $5.2 \mathrm{wt} \%$ and $7.2 \mathrm{wt} \%$ for SZ-1 and SZ-2, respectively, if we assume that the $\mathrm{SO}_{4}{ }^{2-}$ group occupies an area of $0.31 \mathrm{~nm}^{2}$ corresponding to its kinetic diameter [42]. However, the monolayer coverage depends on the assumed sulfate structure. In general, a higher sulfate density on the surface may further more condensed structures as, e.g., pyrosulfates. Hence, on the surface of SZ-1 more pyrosulfate configurations may exist than on the surface of SZ-2, which would explain the higher activity of SZ-1.

The results confirm that highly active catalysts can be obtained with tetragonal materials; however, not all tetragonal materials are necessarily highly active. It is additionally required that the exposed facet planes are of the right type and right quality to allow the formation of certain sulfate structures. Interesting in this respect is that excellent promoters such as manganese or iron are incorporated into the tetragonal phase causing a constriction of the lattice [47].

\subsection{Dehydrogenation ability of sulfated zirconia}

The initial step of butane skeletal isomerization has been proposed to be the formation of a surface carbenium ion, but the mechanism of the formation of such an active species is still under debate. On a superacid catalyst, carbenium ions can be formed directly by protonation of alkanes through Brønsted superacid sites and subsequent 
decomposition of the alkanium ions under cleavage of $\mathrm{H}_{2}$, or by hydride abstraction from alkanes through Lewis superacid sites. However, the superacidity of sulfated zirconia has been doubted recently and the formation of carbenium ions was ascribed to protonation of alkene impurities; contribution of this pathway has been confirmed by the dramatical decrease of the isomerization activity after removal of trace amounts of butenes in the feed.

In a preceding study, the dehydrogenation ability of sulfated zirconia was identified during $n$-butane isomerization at $373 \mathrm{~K}$ by detection of butene (with TPD), water (by in situ IR spectroscopy) and $\mathrm{SO}_{2}$ [30]. The in situ generation of butenes has been shown to be the initial step for $n$ butane isomerization reaction. Such a step would be noncatalytic if no pathways for re-oxidation of the sulfur species existed and irreversible if sulfur was lost. However, once an activate intermediate has been formed, the isomerization proceeds in cycles including rearrangement and hydride transfer with generation of new intermediates. Given a high number of cycles per generated butene, a pseudosteady state behavior can be observed.

The results of $n$-butane TPD on SZ- 1 indicate that it is able to oxidatively convert $n$-butane to butene at low temperatures. However, for the catalyst SZ-2, which is inactive for $n$-butane isomerization at low temperature, a discrete butene desorption peak was not observed. Thus, we conclude that the dehydrogenation ability of SZ-1, which leads to the in situ formation of butenes, is responsible for isomerization activity at low temperatures.

Increasing the reaction temperature to $473 \mathrm{~K}$ can effectively overcome the catalytic inactivity of SZ-2, which then shows an activity comparable to that of SZ-1 at $373 \mathrm{~K}$. The activity is related to the oxidative dehydrogenation on SZ-2 at $473 \mathrm{~K}$, either as less active sites become active or surface sulfate structures rearrange with temperature. In this context it should be emphasized that the heterogeneity of sulfated zirconia could lead to a wide spectrum of active sites with only few very active ones being responsible for the reaction at low temperatures.

If the reaction is limited in the generation of alkenes we conclude that at $373 \mathrm{~K} \mathrm{SZ}-2$ is not producing a sufficient quantity of butene in order to start the reaction. Thus, the difference in the generation of alkenes is responsible for the low activity of SZ-2. At $473 \mathrm{~K}$ the production of alkenes is sufficient for both materials and, hence, catalytic activity is found on both. However, the rates of reaction differ for the two materials still by one order of magnitude (SZ-1 $\mathrm{r}=20 * 10^{-2} \mu \mathrm{mol} /(\mathrm{g} . \mathrm{s})$ and SZ-2 $\mathrm{r}=1 * 10^{-2}$ $\mu \mathrm{mol} /(\mathrm{g} . \mathrm{s})$. In this context it should be emphasized that the concentration of Brønsted acid sites on SZ-1 is $50 \%$ higher than on SZ-2. This suggests that the dramatic differences between the two samples add up from a number of subtle effects rather than from one effect.

\subsection{Adsorption sites and nature of interaction with alkanes}

The difference in catalytic activity between the two samples is neither reflected in the number of sites available for alkane adsorption, nor in the differential heats. The projected coverage under our reaction conditions $(5 \mathrm{kPa}) n$ butane is $85-160 \mu \mathrm{mol} \mathrm{g}{ }^{-1}$. The sulfate content of both materials is $9 \mathrm{wt} \%$ or about $938 \mu \mathrm{mol} \mathrm{g}^{-1}$. If a site consisted of a single sulfate group, only about $10-15 \%$ of all sulfate groups would participate under our reaction conditions; for a pyrosulfate group, about $20-30 \%$ of the sulfur would be involved in adsorption of the reactant. This confirms that not all sulfates are active and the catalyst can be destroyed by removal of $40 \%$ of the sulfate [48], and it may explain why it has been so difficult to spectroscopically identify any relevant sulfate structure.

The differential heats of adsorption for all three used alkanes on both catalysts did not deviate significantly from each other. Typically, about $60 \mathrm{~kJ} \mathrm{~mol}^{-1}$ evolved at low coverages and beyond $10 \mu \mathrm{mol} \mathrm{g}{ }^{-1}$, the heats dropped to $45-50 \mathrm{~kJ} \mathrm{~mol}^{-1}$. These values correspond to only about $2-3$ times the heat liberated upon condensation of propane $\left(18.8 \mathrm{~kJ} \mathrm{~mol}^{-1}\right), n$-butane $\left(22.4 \mathrm{~kJ} \mathrm{~mol}^{-1}\right)$ and isobutane $\left(21.3 \mathrm{~kJ} \mathrm{~mol}^{-1}\right)$ [49] and indicate a weak interaction.

The similarity of the heats of adsorption for $\mathrm{C}_{3}$ and $\mathrm{C}_{4}$ alkanes is explainable by an interaction with the surface that does not encompass the entire molecule. An adsorption with the $n$-alkane flat on the surface appears unlikely because of the corrugated nature of the sulfated zirconia surface [46]. The pocket-like interstitial space between the surface sulfate groups may accommodate only part of an alkane in an end-on like fashion.

For the adsorption of $n$-alkanes on the zeolite HSZM-5, the heat of adsorption increases with the chain length; $32 \mathrm{~kJ} \mathrm{~mol}^{-1}$ and $48 \mathrm{~kJ} \mathrm{~mol}^{-1}$ were reported for the adsorption of propane and $n$-butane [50]. The range of $45-$ $60 \mathrm{~kJ} \mathrm{~mol}^{-1}$ for adsorption of propane and isobutane on sulfated zirconia indicates sites that interact more strongly with alkanes than those of the zeolite HZSM-5. Data of $n$ and isobutane adsorption on sulfated zirconia presented by González et al. [51] show a more rapid decline of the heat with coverage to values below $40 \mathrm{~kJ} \mathrm{~mol}^{-1}$ at $30 \mu \mathrm{mol} \mathrm{g}^{-1}$ coverage. The surfaces of SZ-1 and SZ-2 are obviously more homogeneous than those of the catalysts in [Heats of adsorption from calorimetry data can be compared to those accessible through TAP data, and can be used to validate the transferability of TAP results, which are obtained in the Knudsen regime (base pressure $<10^{-9} \mathrm{hPa}$ ), to pressures in the $\mathrm{hPa}$ range. The heats of adsorption of $n$-butane that result from van't Hoff plots of the equilibrium constants given by the ratios of the rate constants for adsorption and desorption were similar for both catalysts, namely, about $52-53 \mathrm{~kJ} \mathrm{~mol}^{-1}$. The TAP response curve is an average over all interactions of the molecules in the pulse with the surface, and the obtained heat of adsorption should correspond to an average value. The average heat estimated from the 
calorimetric results is about $50 \mathrm{~kJ} \mathrm{~mol}^{-1}$, indicating perfect agreement between the two techniques.

The heats of adsorption are relatively small and adsorption at $313 \mathrm{~K}$ is reversible within the detection limits of the calorimeter $(<10 \%)$. The values obtained for the heats indicate a weak type of interaction for the majority of the alkane molecules, such as, e.g., hydrogen bonding via induced polarization of the alkane. It has been reported that $n$-alkanes interact with the $\mathrm{OH}$ groups of pure [52] and sulfated zirconia [53]. The bands of sulfate were claimed not to be shifted appreciably after $n$-butane adsorption [54]; after adsorption of $n$-pentane the $\mathrm{S}=\mathrm{O}$ band at $1416 \mathrm{~cm}^{-1}$ was decreased without formation of additional bands. The role of sulfate in the adsorption process is thus not clear, but it appears that alkanes adsorb on OH-groups.

Our results do not reveal an obvious difference in the quality of the sites for reactant adsorption that would allow explanation of the one order of magnitude different catalytic activities. The small heats of adsorption are consistent with the observations made during $n$-butane TPD, which did not show much desorption of butane because it is mostly weakly and thus reversibly adsorbed and is removed during evacuation prior to the TPD. However, the presence of a small amount of sites with a different heat of adsorption cannot be excluded from calorimetry, and these might be the sites that dehydrogenate butane during TPD to give butene(s). The calorimetry results limit the number of sites capable of butane dehydrogenation to $5 \mu \mathrm{mol} \mathrm{g}^{-1}$ or less.

\subsection{Carbenium ions and/or alkoxy groups on the surface at low temperature}

An induction period was always observed during $n$ butane isomerization reaction on sulfated zirconia at low temperature. During this period alkoxy groups (carbenium ions) formed by protonation of butene generated by oxidative conversion are concluded to be accumulated on the catalytic surface (see also ref. [30]). On sulfated zirconia SZ-1, pulse and continuous flow $n$-butane reaction at low temperature showed an identical induction period. The amount of molecules streaming through the catalyst bed in the pulse experiment is only half of that in the continuous flow experiment, indicating that the accumulation of a species by adsorption from the gas phase is not rate determining, as shown previously by Cheung et al. [55]. Rather, changes to the surface or slow conversion of already adsorbed species must be relevant. Furthermore, purging with helium did not affect the transition of the surface into a more active state. We speculate that some of the adsorbed $n$-butane molecules were retained on the surface because they have already been transformed and do no longer interact merely by the weak interaction seen in the calorimetry and TAP experiments; i.e. they could be surface carbenium ions.

The stop-restart method was applied in the deactivation period of $n$-butane isomerization. It is very clear that the active species are stable on the catalyst surface during
He purge even for $5 \mathrm{~h}$. Thus, when the reaction was restarted, the reaction rate in the first minute is much higher compared to that of the continuous reaction, because a large fraction has been converted to tert-butyl carbenium ion and these undergo preferred hydride transfer in this initial stage of the reaction. This is also the reason why the catalytic activity in the first minute when restarting the reaction after 20 and 60 min He purge, is higher than the maximum activity of the continuous flow reaction. During He purge, the surface sec-butyl carbenium ion undergoes skeletal isomerization to its isomer, the tert-butyl carbenium ion, in the absence of $n$-butane. This suggests also that the skeletal isomerization not the hydride transfer step is the rate determination step. After restarting the reaction following to He purge for $5 \mathrm{~h}$, the reaction showed an induction period, although the active species is still on the surface, indicating that the long time purge can remove a very small fraction of the surface alkoxy groups/carbenium ions, probably via the decomposition of carbenium ion to its corresponding olefin and a proton.

In the deactivation period, without any butane flow, the deactivation rate of the stop-restart reaction was nearly identical with the continuous flow reaction (at least for 20 and 60 min purge), which implies that the deactivation is due to the decay of the active species. The most plausible reaction is the reaction between olefins desorbing and surface carbenium ions forming larger surface intermediates, which hamper the accessibility to the active sites. The larger surface species also undergo slower hydride transfer. The rapid deactivation limits the application of bare sulfated zirconia in industry application. Thus, usually a noble metal function is additionally introduced and the reaction is operated under hydrogen in order to control the olefin concentration in the reactor.

\section{Conclusions}

Two sulfated zirconia samples with different catalytic activity were fully characterized and investigated with respect to $n$-butane skeletal isomerization. The sulfated zirconia prepared from zirconium hydroxide aged in the solution at room temperature for $1 \mathrm{~h}$ showed much higher activity than that prepared from zirconium hydroxide aged at $373 \mathrm{~K}$ for $24 \mathrm{~h}$. The stoichiometric oxidation (of butane to butene) of these two samples is concluded to be the critical difference determining the variations in catalytic activity. The SZ-2 sample exhibits catalytic activity when the reaction temperature is raised to $473 \mathrm{~K}$, which indicates the dehydrogenation property of sulfated zirconia was dramatically promoted by the higher temperature.

Since both materials are tetragonal and have the same sulfate content, the different reactivity is speculated to either originate from the difference in sulfate density on the surface (consequence of the BET surface areas), or from the difference in the size and the defect structure of the zirconia crystals (revealed by XRD and EXAFS), or from combination of these properties. The number of sites 
for butane oxidative dehydrogenation must be very small (less than $5 \mu \mathrm{mol} / \mathrm{g}$ ), because microcalorimetry experiments prove the interaction with $\mathrm{C}_{3}$ and $\mathrm{C}_{4}$ alkanes to be weak for the majority of sites. Heats of adsorption for $n$ butane determined by calorimetry were about 45$60 \mathrm{~kJ} / \mathrm{mol}$, consistent with estimations from TAP data.

By analysis of the catalytic behavior of the surface active species, the surface alkoxy group/surface carbenium ion, with pulse and stop-restart methods on SZ-1 at $373 \mathrm{~K}$, it was clearly shown that the carbenium ion is very stable under the conditions employed, and the deactivation of sulfated zirconia is due to the decay of carbenium ion species.

\section{References}

1. X.M. Song, A. Sayari, Catal. Rev. Sci. Eng. 38 (1996) 329.

2. K. Arata, Adv. Catal. 37 (1990) 165.

3. G.D. Yadav, J.J. Nair, Micropor. Mesopor. Mater. 33 (1999) 1 .

4. V. Adeeva, H. Liu, B. Xu, W.M.H. Sachtler, Top. Catal. 6 (1998) 61.

5. T. Yamaguchi, K. Tanabe, Y.C. Kung, Mater. Chem. Phys. 16 (1986) 67.

6. C. Sarzanini, G. Sacchero, F. Pinna, M. Signoretto, G. Cerrato, C. Morterra, J. Mater. Chem. 5 (1995) 481.

7. C. Guo, S. Yao, J. Cao, Z. Qian, Appl. Catal. A General 107 (1994) 229.

8. J.R. Sohn, H.W. Kim, J. Mol. Catal. 52 (1989) 361.

9. J.M. Parera, Catal. Today 15 (1992) 481.

10. M.-T. Tran, N.S. Gnep, G. Szabo, M. Guisnet, Appl. Catal. A General 171 (1998) 207.

11. D. Fărcaşiu, J.Q. Li, Appl. Catal. A General 175 (1998) 1.

12. C. Morterra, G. Cerrato, C. Emanuel, V. Bolis, J. Catal. 142 (1993) 349.

13. R.A. Comelli, C.R. Vera, J.M. Parera, J. Catal. 151 (1995) 96.

14. A. Hahn, T. Ressler, R.E. Jentoft, F.C. Jentoft, Chem. Commun. (2001) 537.

15. M. Hino, S. Kobayashi, K. Arata, J. Am. Chem. Soc. 101 (1979) 6439.

16. C. Morterra, G. Cerrato, G. Meligrana, M. Signoretto, F. Pinna, G. Strukul, Catal. Lett. 73 (2001) 113.

17. C.R. Vera, J.M. Parera, J. Catal. 165 (1997) 254.

18. D. Fărcaşiu, J.Q. Li, S. Cameron, Appl. Catal. A General 154 (1997) 173.

19. D. Fărcaşiu, J.Q. Li, Appl. Catal. A General 128 (1995) 97.

20. F.R. Chen, G. Coudurier, J. Joly, J.C. Vedrine, J. Catal. 143 (1993) 616.

21. W. Stichert, F. Schüth, J. Catal. 174 (1998) 242.

22. W. Stichert, F. Schüth, S. Kuba, H. Knözinger, J. Catal. 198 (2001) 277.

23. J.B. Nicholas, J.F. Haw, L.W. Beck, T.R. Krawietz, D.B. Ferguson, J. Am. Chem. Soc. 117 (1994) 12350.

24. J. Zhang, J.B. Nicholas, J.F. Haw, Angew. Chem., Int. Ed. Engl. 39 (2000) 3302.

25. B.S. Umansky, K. Hall, J. Catal. 124 (1990) 97.

26. F. Babou, G. Coudurier, J.-C. Vedrine, J. Catal. 152 (1995) 341.

27. L.M. Kustov, V.B. Kazansky, F. Figueras, D. Tichit, J. Catal. 150 (1994) 143.

28. K.T. Wan, C.B. Khouw, M.E. Davis, J. Catal. 158 (1996) 311.

29. D. Fărcaşiu, A. Ghenciu, J.Q. Li, J. Catal. 158 (1996) 116.

\section{Acknowledgements}

The Deutsche Forschungsgemeinschaft is gratefully acknowledged for supporting the project in the frame of the priority program no 1091 "Bridges between real and ideal systems in heterogeneous catalysis". The authors would like to thank E. Kitzelmann, R.E. Jentoft, T. Ressler and Hasylab at DESY for the XAS and XRD measurements, G. Weinberg for the SEM measurements, R. Schlögl, A. Hofmann and J. Sauer for fruitful discussions. MEL Chemicals kindly provided the $\mathrm{Y}$-stabilized $\mathrm{ZrO}_{2}$.

30. X. Li, K. Nagaoka, L.J. Simon, A. Hofmann, J. Sauer, J.A. Lercher, J. Chem. Phys. B, submitted for publication (2004).

31. J.E. Tabora, R.J. Davis, J. Am. Chem. Soc. 118 (1996) 12240.

32. S. Hammache, J.G. Goodwin Jr., J. Catal. 211 (2002) 316.

33. J.E. Tabora, R.J. Davis, J. Catal. 162 (1996) 125.

34. A. Sayari, Y. Yang, X. Song, J. Catal. 167 (1997) 346.

35. R. Ahmad, J. Melsheimer, F.C. Jentoft, R. Schlögl, J. Catal. 218 (2003) 365.

36. K.B. Fogash, R.B. Larson, M.R. Gonzalez, J.M. Kobe, J.A. Dumesic, J. Catal. 163 (1996) 138.

37. H. Liu, V. Adeeva, G.D. Lei, W.M.H. Sachtler, J. Mol. Catal. A 100 (1995) 35.

38. P. Canton, R. Olindo, F. Pinna, G. Strukul, P. Riello, M. Meneghetti, G. Cerrato, C. Morterra, A. Benedetti, Chem. Mater. 13 (2001) 1634.

39. T. Ressler, J. Synchrotron Rad. 5 (1998) 118.

40. L.C. Josefowicz, H.G. Karge, E.N. Coker, J. Phys. Chem. 98 (1994) 8053.

41. J.T. Gleaves, G.S. Yablonski, Y. Schuurman, Appl. Cat. A: General 160 (1997) 55.

42. N. Katada, J. Endo, K. Notsu, N. Yasunobu, N. Naito, M. Niwa, J. Phys. Chem. B 104 (2000) 10321.

43. S. Matysik, C. Breitkopf, H. Papp, submitted.

44. C.-Y. Hsu, C.R. Heimbuch, C.T. Armes, B.C. Gates, J. Chem. Soc. Chem. Commun. 1645 (1992).

45. X. Yang, R.E. Jentoft, F.C. Jentoft, Catal. Lett., in press.

46. A. Hofmann, J. Sauer, J. Phys. Chem. B 108 (2004) 14652.

47. F.C. Jentoft, A. Hahn, J. Kröhnert, G. Lorenz, R.E. Jentoft, T. Ressler, U. Wild, R. Schlögl, J. Catal. 224 (2004) 124.

48. X. Li, K. Nagaoka, J.A. Lercher, J. Catal., in print (2004).

49. D'Ans Lax, Taschenbuch für Chemiker und Physiker (Handbook for chemists and physicists), $4^{\text {th }}$ ed., Vol. II, Organic compounds, Springer, Berlin, 1983.

50. F. Eder, M. Stockenhuber, J.A. Lercher, J. Phys. Chem. B 101 (1997) 5414.

51. M.R. González, K.B. Fogash, J.M. Kobe, J.A. Dumesic, Catal. Today 33 (1997) 303.

52. B. Klose, Thesis (Diplomarbeit), TU München 2001.

53. E.A. Paukshtis, N.S. Kotsarenko, V.P. Shmachkova, Catal. Lett. 69 (2000) 189.

54. F. Babou, G. Coudurier, J.C. Vedrine, J. Catal. 152 (1995) 341.

55. T.-K. Cheung, J.L. d'Itri, B.C. Gates, J. Catal. 151 (1995) 464. 